Список використаних джерел

1. Яцків Я.С., Александров О.М., Вавилова І.Б. [та ін.] Загальна теорія відносності: випробування часом.- Київ: ГАО НАН України, 2005.

2. Яцків Я.С., Александров О.М., Вавилова І.Б. [та ін.] Загальна теорія відносності: горизонти випробувань. - Київ: ВАІТЕ, 2013.

3. Александров А.Н., Вавилова И.Б., Жданов В.И. [и др.] Общая теория относительности: признание временем. - К.: Наукова Думка, 2015.

4. Novosyadlyi B., Pelykh V., Shtanov Yu., Zhuk A. Dark energy and dark matter of the universe: in three volumes / Ed. V. Shulga. - Vol. 1: Dark matter: Observational evidence and theoretical models. K.: Akademperiodyka, -2013.

5. Nojiri S., Odintsov S.D. , Tsujikawa S. Properties of singularities in (phantom) dark energy universe // Phys.Rev.D71:063004 (2005).

6. Nojiri S., Odintsov S.D. Modified gravity with negative and positive powers of the curvature: unification of the inflation and of the cosmic acceleration // Phys.Rev.D68:123512 (2003).

7. Bamba K., Odintsov S.D. Universe acceleration in modified gravities: $F(R)$ and $F(T)$ cases// arXiv:1402.7114 [hep-th] (2014).

8. Jenkovszky L.L., Zhdanov V.I., Stukalo E.J. Cosmological model with variable vacuum pressure. Phys.Rev.D90, 023529 (2014).

9. Caldwell R.R., Kamionkowski M., Weinberg N.N. Phantom Energy: Dark Energy with w<-1 Causes a Cosmic Doomsday. Phys.Rev.Lett., vol. 91, Issue 7, id. 071301 (2003).

Надійшла до редколегії 30.11.14

V. Zhdanov, Dr. Sci., Prof.

S. Dylda, stud. phys. fac.,

National Taras Shevchenko University of Kyiv

\title{
QUALITATIVE ANALYSIS OF A COSMOLOGICAL EVOLUTION IN A HYDRODYNAMICAL MODEL WITH A BAROTROPIC EQUATION OF STATE
}

We study a qualitative behavior of the scale factor and energy density in a hydrodynamical model of a homogeneous isotropic Universe with a general barotropic equation of state (EOS). We relax conditions on EOS as compared with the paper by Jenkovszky et al., [Phys. Rev. D 90,023529 (2014)] and to include the cases of two or more points of zero specific enthalpy. We present a classification of possible scenarios with an asymptotically exponential inflation, analogs of the Big Rip in the future and in the past, singularity free bouncing solutions and oscillating Universes.

В. Жданов, д-р. физ.-мат. наук, проф.,

С. Дылда, студ. физ. ф-та,

Киевский национальный университет имени Тараса Шевченко

\section{КАЧЕСТВЕННЫЙ АНАЛИЗ КОСМОЛОГИЧЕСКОЙ ЭВОЛЮЦИИ В ГИДРОДИНАМИЧЕСКОЙ МОДЕЛИ С БАРОТРОПНЫМ УРАВНЕНИЕМ СОСТОЯНИЯ}

Мы исследуем качественное поведение маситабного фактора и плотности энергии в гидродинамической модели однородной изотропной Вселенной с общим баротропным уравнением состояния (УС). Анализ проводится при условии на УС более общем, чем это было сделано ранее в работе Jenkovszky et al., [Phys. Rev. D 90, 023529 (2014)], в т. ч., допускаются случаи с двумя и более точками, где удельная энтальпия космологической жидкости равна О. Приводится качественная классификация, вклющающая в себя возможные сценарии космологической эволюции с ассимпотически экспоненциальной инфляцией, аналоги "Большого Разрыва" в будущем или в прошлом, решения без сингулярностей и осциллирующие вселенные.

УДК 523.64

В. Пономаренко, канд. фіз.-мат. наук, А. Сімон, інженер 2 кат.,

К. Чурюмов, д-р фріз.-мат. наук, профр. Астрономічна обсерваторія Київського національного університету імені Тараса Шевченка

\section{ПАРАMЕТРИ ПИЛУ ТА ГАЗУ У КОМІ КОМЕТ C/2014 Q2 (LOVEJOY) I C/2013 US10 (CATALINA)}

Представлено результати спостережень і досліджень довгоперіодичних комет C/2014 Q2 (Lovejoy) i C/2013 US10 (Catalina) на основі оптичних спектрів з середньою роздільною здатністю ( $/ \Delta \lambda \approx 1200)$. Спектри були отримані у лютому та грудні 2015 року за допомогою телескопа A3T-14 (D=0.48 м, F= 7.7 м) i спектрографа ACח-9 на спостережній станиії "Лісники" Астрономічної обсерваторії Київського національного університету імені Тараса Шевченка. На основі отриманого спектрального матеріалу була проведена ідентифікація спектральних емісійних смуг. Знайдено деякі фізичні параметри нейтральної газової та пилової кометних атмосфер. Побудовано розподіл загального і відбитого потоку енергії вздовж щілини спектрографа. Обчислено потоки, кількість молекул та газопродуктивність для основних молекулярних емісій, відносну пилопродуктивність.

Особливості спостережень комет C/2014 Q2 (Lovejoy) і C/2013 US10 (Catalina) та обробки їх спектрів. Комета C/2014 Q2 (Lovejoy) - довгоперіодична комета (ДПК), яка була відкрита 17 серпня 2014 р. астрономом Тері Лавджоєм з Бризбена (Австралія) з використанням 0.2-метрового телескопа "Celestron C8" (Шмідта-Касегрена). Комета стала п'ятою, яку відкрив Лавджой. Комета C/2014 Q2 була виявлена при видимій зоряній величині $T=15^{\mathrm{m}}$ в південному сузір'ї Корми [1]. Спостереження комети Lovejoy були виконані нами за допомогою телескопарефлектора АЗТ-14 ( $D=0.48$ м, $F=7.7$ м), підвісного призмового спектрографа АСП-9 $(\lambda / \Delta \lambda \approx 1200)$ та ПЗ3 Starlight SXV-H35 (4008x2672 пікселі, 9x9 мкм/піксель). На момент спостережень, комета C/2014 Q2 знаходилася на геліоцентричній відстані $r=1.32$ а.о., геоцентричній відстані $\Delta=1.09$ а.о., мала інтегральну зоряну величину $T=5.2^{\mathrm{m}}$, кут елонгації складав S-O-T $=78^{\circ}$, фазовий кут S-T-O $=47^{\circ}$. Отримано 12 спектрів комети в спектральному діапазоні $\lambda \Lambda=3600-7600 \AA \AA$. 


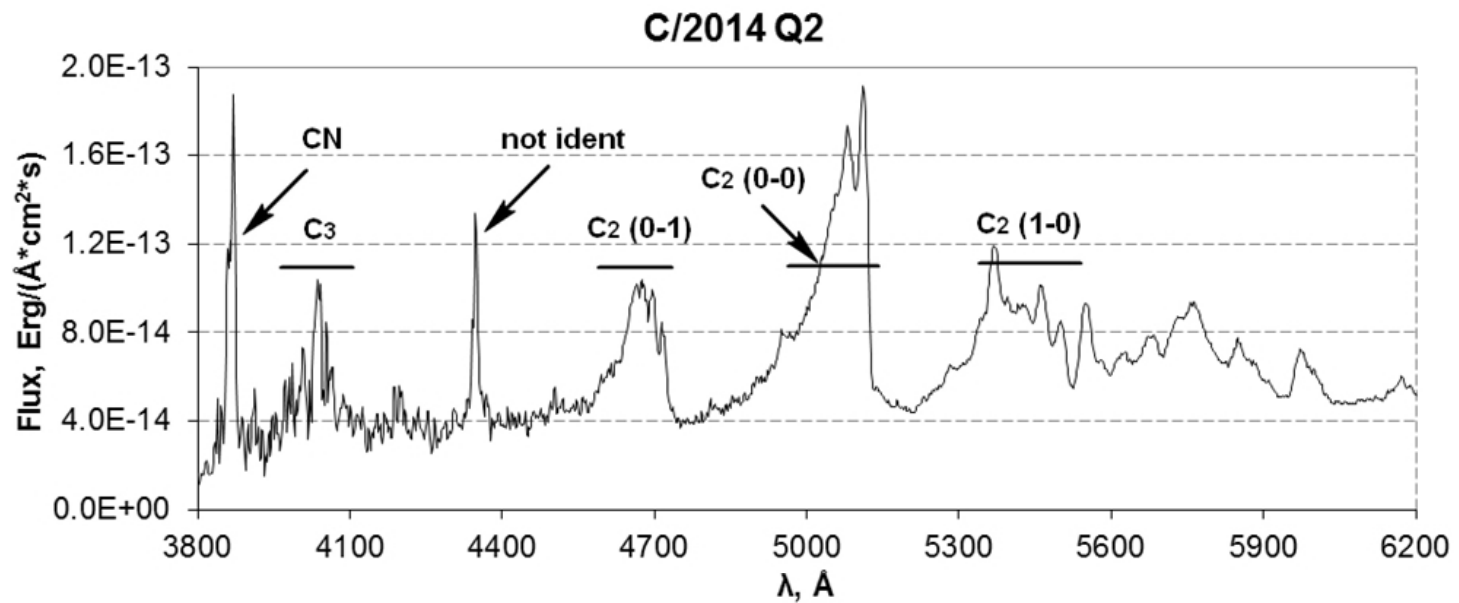

Рис. 1. Емісії в призмовому спектрі комети C/2014 Q2 (Lovejoy)

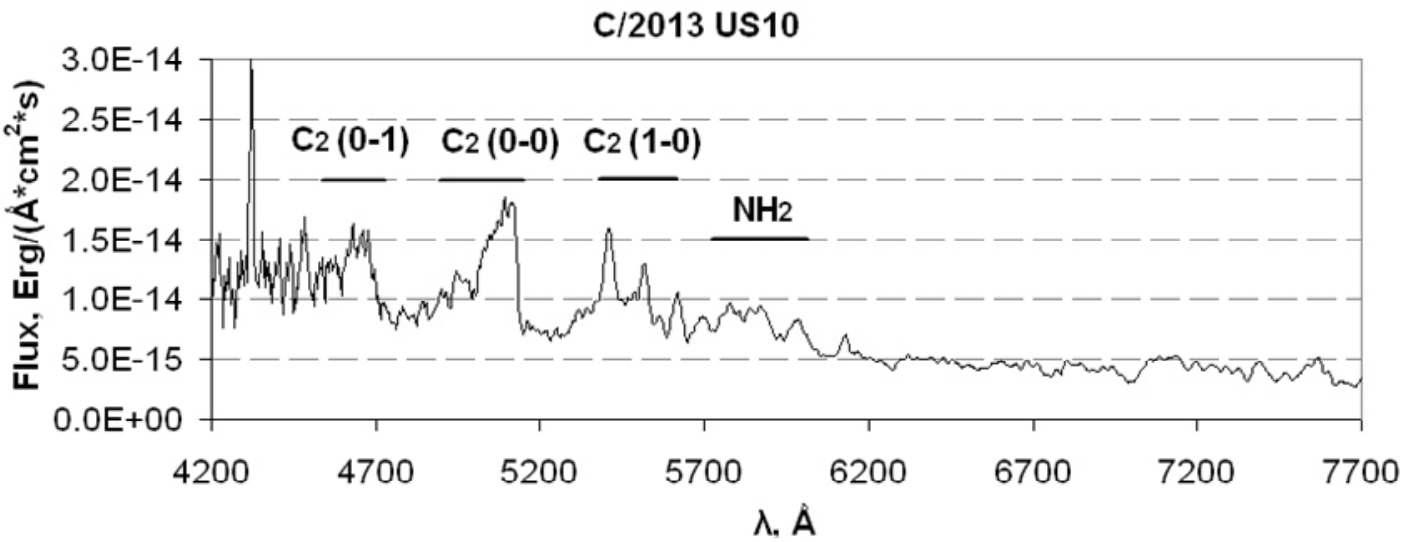

Рис. 2. Емісії в призмовому спектрі комети C/2013 US10 (Catalina)

Комета C/2013 US10 (Catalina) - ДПК, яка була відкрита Р.А. Ковальським 31 жовтня 2013 р. за допомогою 0.67-метрового телескопа Шмідта-Касегрена в межах програми пошуку нових комет і астероїдів - Сatalina Sky Survey. До проходження по внутрішній Сонячній системі (епоха 1950), C/2013 US10 мала орбітальний період у декілька мільйонів років. 17.01.2016 р. комета Catalina пройшла на відстані від Землі $\Delta=0.72$ а.о. В цей час блиск комети складав $T \approx 6^{\mathrm{m}}$ [2]. Для спостережень комети C/2013 US10 було використано те саме обладнання, що і для спостережень C/2014 Q2. На момент спостережень Catalina знаходилася на геліоцентричній відстані $r=1.08$ а.о., геоцентричній відстані $\Delta=1.06$ а.о., мала інтегральну зоряну величину $T=6.5^{\mathrm{m}}$, кут елонгації складав S-O-T $=64^{\circ}$, фразовий кут S-T-O = 55 . Було отримано 3 спектри комети в спектральному діапазоні $\lambda \lambda=3800-7700 \AA \AA$.

На рис. 1 та рис. 2 зображені ділянки призмових спектрів комет C/2014 Q2 (Lovejoy) і C/2013 US10 (Catalina) відповідно, з ототожненими емісійними смугами. Над спектрами були виконані всі базові редукції, які включали врахування bias (підкладки), dark (накопиченого теплового заряду), вкладу космічних частинок, розсіяного світла в спектрографрі і калібровку за довжинами хвиль. Потоки енергії у спектрах подано у абсолютних одиницях.

Потоки енергії та газопродуктивність молекул CN, C 3 , C 2 в кометах C/2014 Q2 (Lovejoy) i C/2013 US10 (Catalina). Обробка спектрів комет проводилась в декілька етапів. Спочатку над спектрами комет були виконані всі базові редукції. Потім для спектрів комет C/2014 Q2 (Lovejoy) і C/2013 US10 (Catalina), шляхом виокремлення і складання інтенсивностей емісійних ліній, було підраховано потоки енергії $(I)$, кількість молекул на промені зору $(M(\rho))$, газопродуктивність $(Q)$ для смуг CN (3850-3900 А̊), $C_{3}(4020-4100 \AA \AA), C_{2}(5060-5200 \AA \AA)$. Діапазони довжин хвиль вибрано у відповідності до смуг пропускання кометних фільтрів НВ (виготовлених для програми дослідження комет у зв'язку з проходженням перигелію кометою C/1995 О1 (Hale-Bopp) у 1997 р.) [3]. Для інших смуг оцінка не проводилася, оскільки вони виявилися дуже слабкими, що вносило додаткові похибки. Для отримання результату використовувалися приведені нижче параметри і фрормули:

$$
M(\rho)=\frac{4 \pi \cdot l}{g \cdot \Omega}
$$

де $M(\rho)$ - кількість молекул у зоні видимості діафрагми або щілини спектрографа, I - потік енергії від смуги на одиницю площі $\left(\mathrm{cm}^{2}\right)$ дзеркала телескопа, $g$ - фактор фрлуоресценції ( $g / 4 \pi$ - енергія, що перевипромінюється однією молекулою за секунду в межах тілесного кута 1 стерадіан), $\Omega$ - тілесний кут, який визначається проекцією одиниці площі приймача випромінювання на небесну сореру.

Оскільки спостережний матеріал був отриманий зі щілиною спектрографа, а не діафрагмою, $M(\rho)$ зазнало перетворень: 


$$
M^{\prime}(\rho)=\frac{M(\rho) \cdot \pi \rho^{2}}{a b},
$$

де $а$ та $b$ - висота та ширина щілини спектрографа, $\rho$ - відстань від центра до краю діафрагми. Нам потрібно знайти співвідношення між величинами $a, b$ та $\rho$. Спад інтенсивності нейтральної тимчасової газової атмосфери в межах ділянки щілини спектрографа з якої отримувалась інформація був незначним, оскільки характерні масштаби для досліджуваних молекул значно перевищували розміри щілини за висотою ( $\approx 10 ")$ та шириною ( $\approx$ 8"). Тож зв'язок можна знайти з рівності площ щілини спектрографа та діафрагми:

$$
\pi \rho^{2}=a b \rightarrow \rho=\sqrt{\frac{a b}{\pi}}
$$

звідки випливає:

$$
\frac{Q}{v}=\frac{M(\rho)}{\rho \cdot F(\mu, x)}=\frac{M(\rho)}{F(\mu, x)} \cdot \sqrt{\frac{\pi}{a b}}
$$

де

$$
\mu=\frac{\beta_{1}}{\beta_{2}} ; x=\rho \beta_{2} ; \beta_{1}=\frac{1}{L_{1}} ; \beta_{2}=\frac{1}{L_{2}} ; F(\mu, x)=\int_{x}^{\mu x} K_{0}(y) d y+x^{-1}\left(1-\mu^{-1}\right)+K_{1}(\mu x)-K_{1}(x) ;
$$

$K_{0}$ та $K_{1}$ - циліндричні функції Макдональда 0 і 1 порядків; $L_{1}$ та $L_{2}$ - характерні масштаби (пробіги) для батьківських та дочірніх молекул відповідно; $F(\mu, x)$ - функція Хазера; $v$ - швидкість молекул [4].

У табл. 1 подано константи, які використовувалися в розрахунках для розглянутих комет і їх залежність від геліоцентричної відстані [5]. Також було враховано вплив геліоцентричної швидкості комети на розрахунок газопродуктивності CN [6].

Таблиця 1

Характерні масштаби та фактори флуоресценції для основних емісійних смуг

\begin{tabular}{|c|c|c|c|}
\hline & $\mathbf{C N}(\mathbf{3 8 5}-\mathbf{3 9 0} \mathbf{~ H M})$ & $\mathbf{C}_{3}(\mathbf{4 0 2}-\mathbf{4 1 0} \mathbf{~ H M})$ & $\mathbf{C}_{\mathbf{2}}(\mathbf{5 0 6 - 5 2 0} \mathbf{~ H M})$ \\
\hline$L_{1}, \mathrm{KM}$ & $1.3 \times 10^{4}$ & $6.0 \times 10^{3}$ & $2.2 \times 10^{4}$ \\
\hline$L_{2}, \mathrm{KM}$ & $2.1 \times 10^{5}$ & $8.9 \times 10^{4}$ & $6.6 \times 10^{4}$ \\
\hline$L(r)$ & $L_{1} \times r^{1.3} ; L_{2} \times r^{0.6}$ & $L_{1} \times r^{0.8} ; L_{2} \times r^{2.8}$ & $L_{1} \times r^{1.4} ; L_{2} \times r^{2.0}$ \\
\hline$g,{\mathrm{epr} \times \mathrm{C}^{-1} \times \mathrm{MO}^{-1}}^{-1}$ & $3.8 \times 10^{-13}$ & $1 \times 10^{-12}$ & $4.5 \times 10^{-13}$ \\
\hline$g(r)$ & \multicolumn{3}{|c|}{$g \times r^{-2}$} \\
\hline
\end{tabular}

Результати по газопродуктивності комет C/2014 Q2 (Lovejoy) і C/2013 US10 (Catalina) подано у табл. 2. Оскільки, на даний час відсутні дані інших авторів по газопродуктивності досліджуваних у статті комет, у табл. 2 також приведено порівняння з іншими кометами, що знаходилися на подібних геліоцентричних відстанях [7, 8]. 3 таблиці чітко видно, що значення газопродуктивності досліджуваних комет мають кореляцію з іншими об'єктами таблиці. Винятком є дещо нижча за очікувану продуктивність CN комети C/2014 Q2.

\begin{tabular}{|c|c|c|c|c|}
\hline Комета & r, a. 0. & $Q_{\mathrm{CN}}$, мол/с & $Q_{\mathrm{c} 3}$, мол/с & $Q_{\mathrm{c} 2}$, мол/с \\
\hline $81 \mathrm{P}$ & 1.63 & $2.09 \times 10^{25}$ & $2.1 \times 10^{24}$ & - \\
\hline $103 \mathrm{P}$ & 1.06 & $9.44 \times 10^{24}$ & $9.86 \times 10^{23}$ & $2.12 \times 10^{25}$ \\
\hline C/2009 K5 & 1.50 & $6.99 \times 10^{25}$ & $5.35 \times 10^{24}$ & $3.65 \times 10^{26}$ \\
\hline $\mathrm{C} / 2014 \mathrm{Q} 2$ & 1.32 & $1.84 \times 10^{25}$ & $7.16 \times 10^{24}$ & $2.40 \times 10^{26}$ \\
\hline $\mathrm{C} / 2013$ US10 & 1.08 & - & - & $8.89 \times 10^{25}$ \\
\hline
\end{tabular}

Газопродуктивність основних емісійних смуг комет C/2014 Q2 (Lovejoy), C/2013 US10 (Catalina)

таблиця 2 та інших об'єктів порівняння

Властивості пилового континууму комет C/2014 Q2 (Lovejoy) i C/2013 US10 (Catalina). Важливим параметром пилової коми комети є Afo (відносна пилопродуктивність). Пилопродуктивність також розраховувалася для діапазонів довжин хвиль вузькосмугових кометних фільтрів НВ. Оскільки даний метод був розроблений Фархамом та ін. [3] для вузькосмугових кометних фрільтрів (UC, $\lambda \lambda=340-350$ нм; BC, $\lambda \lambda=442-450$ нм; GC, $\lambda \lambda=522-530$ нм; RC, $\lambda \lambda=708-718$ нм), його використання зі щілиною спектрографра вимагало адаптації. Для обчислення Afp у фрільтрах використувалися наступні параметри і формули:

$$
A f_{\rho}=\frac{q_{f} r^{2} \Delta \cdot F_{f}}{\theta}
$$

де $r$ та $\Delta$ - відповідно геліо- та геоцентрична відстань до комети (в а.о.); $\theta$ - апертура в кутових секундах (діаметр діафрагми); $q_{f}$ - коефіцієнт перетворення для фільтра, що використовується; $F_{f}$ - спектральна густина (потік енергії,

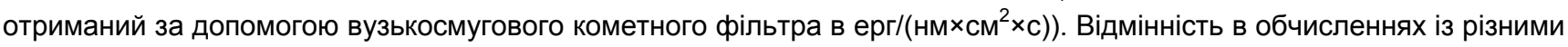
фрільтрами пов'язана лише з $q_{f}$.

Пилова кома комети поширюється на значно менші відстані ніж тимчасова газова атмосфера. Порядок розмірів пилової кометної коми відповідав кутовим розмірам щілини спектрографа. Тому, для отримання рівномірного спаду інтенсивності за висотою та шириною щілини, потрібно розглядати її вписаною у діафрагму. Адаптоване для щілини спектрографра рівняння матиме вигляд:

$$
\theta=\sqrt{n^{2}+m^{2}} ; F_{f}=\frac{F_{f}^{\prime} \pi \theta^{2}}{4 m n}=\frac{F_{f}^{\prime} \cdot \pi\left(n^{2}+m^{2}\right)}{4 m n} ;
$$


звідки

$$
A \rho_{\rho_{f}}=\frac{q_{f} r^{2} \Delta \cdot F_{f}^{\prime} \pi\left(n^{2}+m^{2}\right)}{4 m n \cdot \sqrt{n^{2}+m^{2}}}=\frac{q_{f} r^{2} \Delta \cdot F_{f}^{\prime} \pi \sqrt{\left(n^{2}+m^{2}\right)}}{4 m n}
$$

де $F_{f}$ - спектральна густина, яка відповідає конкретному фільтру (з діаметром, рівним діагоналі щілини); $F_{f}^{\prime}-$ спектральна густина для щілини спектрографра в діапазоні довжин хвиль кометного фрільтра; $m$ - ширина щілини у кутових секундах ("), $n$ - протяжність області знімка вздовж щілини, з якої зчитується спектр кометної коми ("); $\theta$ - діаметр діафрагми (").

Параметри, що використовувалися для обчислення $A f \rho$

Таблиця 3

\begin{tabular}{|c|c|c|c|c|}
\hline Фільтр & $\lambda \lambda, \AA \AA A$ & ө, (") для C/2014 Q2 & ө, (") для C/2013 US10 & $q_{f}$ \\
\hline $\mathrm{BC}$ & $4420-4490$ & 12.8 & 8.2 & $1.276 \times 10^{17}$ \\
\hline GC & $5230-5290$ & 12.8 & 8.2 & $1.341 \times 10^{17}$ \\
\hline $\mathrm{RC}$ & $7100-7170$ & 12.8 & 8.2 & $1.975 \times 10^{17}$ \\
\hline
\end{tabular}

В табл. 3 наведені значення величин, що використовувалися для обчислення відносної пилопродуктивності (діапазони довжин хвиль вузькосмугових кометних фільтрів, діаметр діафрагми в яку вписана ділянка щілини спектрографра з якої відбувалося зчитування ( $\theta)$, коефіцієнт перетворення фрільтра $\left.\left(q_{f}\right)\right)$.

В табл. 4 представлені відносні пилопродуктивності для досліджуваних комет (C/2014 Q2, C/2013 US10), а також для трьох комет сімейства Юпітера (КСЮ) та трьох ДПК для порівняння [8]. Нажаль на даний момент відсутні дані інших авторів для порівняння отриманих результатів з відносної пилопродуктивності комет C/2014 Q2 і C/2013 US10. 3 табл. 4 можна зробити висновок, що пилопродуктивність об'єктів дослідження була порівняно невисокою як для ДПК. Це може бути пов'язано з тим, що спостереження були проведені після проходження кометами Lovejoy i Catalina перигелію. Більшість пилу, що вірогідно знаходилася на поверхні, під впливом зростаючої газопродуктивності могла бути піднята, оскільки ці комети вперше настільки близько підходили до Сонця. Це б спричинило зменшення пилопродуктивності після проходження перигелію, адже в цьому випадку продуктивність в основному продовжувала підтримуватися пилом з надр. Підтвердження цієї точки зору також є у табл. 4. Afo комети C/2009 P1 до проходження перигелію значно вище (незважаючи на більшу геліоцентричну відстань). Варто звернути увагу й на те, що відносна пилопродуктивність комети C/2014 Q2 зростає з довжиною хвилі (це притаманно більшості комет і вказує на почервоніння кометного континуума). Afo C/2013 US10 змінюється у порівняно вузькому діапазоні (це вказує на нейтральний колір кометного континуума).

Порівняння Afo у кометах C/2014 Q2 (Lovejoy) і C/2013 US10 (Catalina) з іншими КСЮ та ДПК

Таблиця 4

\begin{tabular}{|c|c|c|c|c|c|}
\hline Комета & r, a.o. & $\Delta$, a.o. & $\lg A f \rho_{\mathrm{BC}}$ & $\lg A f \rho_{\mathrm{GC}}$ & $\lg A f \rho_{\mathrm{RC}}$ \\
\hline $22 \mathrm{P}$ & 1.77 & 0.78 & - & 3.019 & 3.274 \\
\hline $81 \mathrm{P}$ & 1.63 & 0.68 & - & 3.815 & 3.733 \\
\hline $103 \mathrm{P}$ & 1.06 & 0.13 & - & 1.794 & 1.899 \\
\hline C/2006 W3 & 3.13 & 2.33 & 4.693 & 4.731 & 4.724 \\
\hline C/2009 K5 & 1.50 & 1.43 & - & 3.901 & 3.811 \\
\hline C/2009 P1 & $\begin{array}{l}2.88 \\
2.09\end{array}$ & $\begin{array}{c}2.5 \\
1.61\end{array}$ & $\begin{array}{c}4.673 \\
-\end{array}$ & $\begin{array}{c}- \\
3.712\end{array}$ & $\begin{array}{c}- \\
3.685\end{array}$ \\
\hline $\mathrm{C} / 2014 \mathrm{Q} 2$ & 1.32 & 1.09 & 3.09 & 3.20 & 3.36 \\
\hline $\mathrm{C} / 2013$ US10 & 1.08 & 1.06 & 2.98 & 2.74 & 2.75 \\
\hline
\end{tabular}

Висновки. За допомогою телескопа АЗТ-14 спостережної станції "Лісники" було отримано оптичні спектри з середньою роздільною здатністю. Якість отриманого спектрального матеріалу дозволила з достатньою точністю оцінити газопродуктивність молекул $\mathrm{C}_{2}, \mathrm{C}_{3}, \mathrm{CN}$ та відносну пилопродуктивність. Значення газопродуктивності $€$ характерними для геліоцентричних відстаней на яких знаходилися комети. Доволі низьке значення відносної пилопродуктивності можна пояснити тим, що комети спостерігалися після проходження ними перигелію.

Список використаних джерел

1. [Електронний ресурс] Режим доступу до ресурсу: https://ru.wikipedia.org/wiki/C/2014_Q2_(\%D0\%9B\%D0\%B0\%D0\%B2\%D0\%B4\%D0\%B6\% D0\%BE\%D1\%8F).

2. [Електронний ресурс] Режим доступу до ресурсу: https://ru.wikipedia.org/wiki/C/2013_US10.

3. Farnham T.L. The HB Narrowband Comet Filters: Standard Stars and Calibrations / T.L. Farnham, D.G. Schleicher, M.F. A'Hearn // Icarus. - 2000. - Vol. 147. - P. 180-204.

4. Краснопольский В.А. Физика свечения атмосфер планет и комет // М.: Наука, 1987. - 304 c.

5. Langland-Shula L.E. Comet classification with new methods for gas and dust spectroscopy / L.E. Langland-Shula, G.H. Smith // Icarus - 2011. - Vol. 213. - P. 280-322.

6. Tatum J.B. Cynogen radiance/column-density ratio for comets calculated from the Swings effect / J.B. Tatum // Astron. Astrophys. - 1984. Vol. $135 .-$ P. 183-187.

7. Чурюмов К.И., Пономаренко В.О., Клещонок В.В., Мозгова А.М., Кузнєцов М.А. Оптична спектроскопія комети $103 \mathrm{P} / \mathrm{Hаrtleу} 2$ в жовтні 2010 року // Вісник астрономічної школи - 2012. - т. 8. - № 1-2. - С. 91-95.

8. Пономаренко В.О. Спектральні особливості вибраних комет сімейства Юпітера та довгоперіодичних комет зі зворотним рухом: дис. канд. фріз.-мат. наук: 01.03 .03 / Пономаренко Василь Олександрович - Київ, 2015. - 128 с. 
Ponomarenko V., Ph. D.

Simon A., eng. 2 кат.,

K. Chiuriumov, Dr. Sci., professor

Astronomical Observatory of National Taras Shevchenko University of Kyiv

\section{PARAMETERS OF DUST AND GAS IN THE COMMA OF THE COMETS C/2014 Q2 (LOVEJOY) I C/2013 US10 (CATALINA)}

The observations and research of the long periodic comets C/2014 Q2 (Lovejoy) and C/2013 US10 (Catalina) by optical spectra with an average resolution $(N \Delta \Lambda \approx 1200)$ are presented. The spectra were obtained in February and December 2015 using the telescope $A Z T-14(D=0.48 m, F=7.7 m)$ and the spectrograph ASP-9 at the station Astronomical Observatory of Taras Shevchenko National University of Kyiv "Lisnyky". On the basis of obtained spectral material was carried the identification of spectral emission bands. Calculated some physical parameters of neutral gas cometary atmosphere and dusty cometary atmosphere. Built distribution of general and reflected energy along the slit of the spectrograph. Calculated flows, the number of molecules and gas productivity for basic molecular emissions, relative dust productivity.

В. Пономаренко, канд. физ.-мат. наук,

А. Симон, инженер 2 кат.,

К. Чурюмов, д-р физ.-мат. наук, проф.

Астрономическая обсерватория Киевского национального университета

имени Тараса Шевченко

\section{ПАРАМЕТРЫ ПЫЛИ И ГАЗА В КОМЕ КОМЕT C/2014 Q2 (LOVEJOY) И C/2013 US10 (CATALINA)}

Представлены результаты наблюдений и исследований долгопериодических комет C/2014 Q2 (Lovejoy) u C/2013 US10 (Catalina) на оcнове оптических спектров со средней разделительной способностью (N/A $\approx 1200)$. Спектры были получены в феврале и декабре 2015 года с помощью телескопа АЗТ-14 (D = 0.48 м, F = 7.7 м) и спектрографа АCП-9 на наблюдательной станции "Лесники" Астрономической обсерватории Киевского национального университета имени Тараса Шевченко. На основе полученного спектрального материали была проведена идентификация спектральных эмиссионных полосс. Найдены некоторые физические параметрв нейтральной газовой и пылевой кометных атмосфер. Построено распределение общего и отраженного потока энергии вдоль щели спектрографа. Вычислены потоки, количество молекул и газопродуктивность для основных молекулярных эмиссий, относительная пылепродуктивность.

УДК 521.95, 521.96, 52-14

И. Эглитис, канд. физз.-мат. наук,

М. Эглите, мл. науч. сотрудник Институт астрономии Латвийского университета, Рига В. Андрук, науч. сотрудник,

Л. Пакуляк, канд. физ.-мат. наук Главная астрономическая обсерватория НАН Украины, Киев

\section{U-ВЕЛИЧИНЫ ЗВЕЗД И ГАЛАКТИК ИЗ ОЦИФРОВАННЫХ АСТРОНЕГАТИВОВ ТЕЛЕСКОПА ШМИДТА В БАЛДОНЕ}

Выполнена оцифровка и обработка нескольких десятков пластинок из стеклотеки 1,2 м телескопа Шмидта в Балдоне, экспонированных в U полосе Джонсона. Для оцифровки использованы сканеры Epson Expression, обработка выполнена в пакете LINUX/MIDAS/RAMAFOT. Точность определения положений звезд Tychо2 составляет 0,1 ", точность построения характеристических кривых в U-полосе заключена в пределах 0,1-0,2 ${ }^{m}$.

Введение. Наблюдения в ультрафиолетовой (UV) полосе спектра в общем случае выполняются вблизи вспыхивающих или сверхновых звезд, на участках с активными ядрами галактик, в областях звездообразования и в полях со скоплениями. Особенно много UV данных в работах по исследованию переменных типа карликовых новых, квазаров и черных дыр [8; 9]. Однако, как следует из данных каталогов и публикаций VisieR Страсбургского центра астрономических данных, в целом UV наблюдений значительно меньше, чем, например, в B, V или R полосах.

Обсерватория в Балдоне Астрономического института Латвийского университета хранит коллекцию из 22 тысяч фотографических пластинок, полученных на 1,2 м телескопе Шмидта. Площадь неба, которую охватывает каждая из пластинок, составляет 19 квадратных градусов и содержит от 10 до 50 тысяч изображений небесных объектов. Масштаб изображений составляет 72 "/ мм.

Наблюдательный материал и его оцифровка. Архив телескопа Шмидта насчитывает 734 пластинки в 253 областях неба, отснятых в UV полосе, близкой к стандартной U Джонсона. При наблюдениях использовалась комбинация эмульсий ORWO ZU21 и ZU2 и фильтров UG1 и UFS3. Пластинки UV коллекции сканировались на сканерах серии EPSON EXPRESSION 10000XL и 11000XL. Предварительные исследования показали, что оптимальным разрешением для сканированных изображений является $1200 \mathrm{dpi} \mathrm{(1,81} \mathrm{"/пх),} \mathrm{дающее} \mathrm{практически} \mathrm{ту} \mathrm{же} \mathrm{точность,} \mathrm{что} \mathrm{и}$ сканы, полученные с более высоким разрешением 2400 dрі. При этом время, затраченное на обработку одной пластинки на высокоскоростном семиядерном компьютере, сокращалось в три раза. Кроме того, существенно уменьшался объем хранимой информации. Особенности поведения сканеров серии EPSON EXPRESSION и их влияние на точность астрометрических и фотометрических результатов исследовалось предварительно в работах [2; 3; 4; 5; 8; $11 ; 24 ; 25]$. Случайные ошибки сканеров для астронегативов телескопа Шмидта оказались равны 0,04 " и 0,015 m для положений и звездных величин соответственно.

Этапы обработки астронегативов. Все изображения были получены в формате .tiff и перед обработкой переведены в формат .fit. Стандартная процедура обработки изображений выполнялась в программном пакете Linux / MIDAS / ROMAFOT, расширенном дополнительными приложениями, разработанными в ГАО НАН Украины для обработки широкоугольных звездных полей. В качестве опорного использовался каталог Тусhо2. Процедура обработки отсканированных астронегативов протестирована и реализована ранее в серии работ $[6 ; 7 ; 9 ; 12 ; 13 ; 14 ; 17$; 18; 19; 26; 28] и состоит из следующих этапов: 